Article

\title{
An Efficient Powder Metallurgy Processing Route to Prepare High-Performance $\beta$-Ti-Nb Alloys Using Pure Titanium and Titanium Hydride Powders
}

\author{
Bhupendra Sharma ${ }^{1, *(\mathbb{D})}$, Sanjay Kumar Vajpai ${ }^{2}$ and Kei Ameyama ${ }^{3}$ \\ 1 Department SI2M, Microstructures et Contraintes, Institute Jean Lamour, University of Lorraine, \\ 54011 Nancy, France \\ 2 Department of Metallurgical \& Materials Engineering, National Institute of Technology Jamshedpur, \\ Jharkhand 831014, India; vajpaisk@gmail.com \\ 3 Department of Mechanical Engineering, College of Science and Engineering, Ritsumeikan University, \\ 1-1-1 Noji-Higashi, Kusatsu-City, Shiga 525-8577, Japan; ameyama@se.ritsumei.ac.jp \\ * Correspondence: bhupendra_sharma2007@yahoo.com; Tel.: +33-771-153-241
}

Received: 13 June 2018; Accepted: 29 June 2018; Published: 4 July 2018

\begin{abstract}
Toward designing a cost-effective advanced powder metallurgy approach, we present a new insight into the efficient utilization of titanium hydride powder, together with pure Ti powder, to prepare high-strength $\beta$-titanium alloys. In the present work, Ti- 40 mass $\% \mathrm{Nb}$ alloy was prepared by mechanical alloying of a mixture of pure Ti, titanium hydride, and $\mathrm{Nb}$ elemental powders, followed by a carefully designed two-step spark plasma sintering. The role of relative amounts of titanium hydride and pure Ti powders during mechanical alloying, and their effect on the microstructural and mechanical properties of the Ti- $40 \mathrm{Nb}$ alloy, have been discussed and elaborated. An increasing amount of titanium hydride results in higher powder yield and smaller resultant powder particle size. Subsequent two-step spark plasma sintering resulted in equiaxed microstructure with primarily $\beta$ phase, wherein the grain size decreased with increasing amounts of titanium hydride powder. The specimen corresponding to alloys prepared using equal amounts of pure Ti and titanium hydride powders resulted in fine-grained structure, exhibiting the best combination of mechanical properties, that is, a combination of highest hardness, high strength, and high ductility.
\end{abstract}

Keywords: $\beta$-type Ti-Nb alloys; two-step spark plasma sintering; titanium hydride; mechanical alloying; powder metallurgy

\section{Introduction}

Titanium and its alloys have been widely accepted for a variety of applications, particularly human body implants and automotive body parts, due to the possibility of achieving a unique combination of outstanding mechanical and chemical properties, together with excellent biocompatibility $[1,2]$. However, the cost-effective bulk processing of near net-shape material remains an important technological issue due to the high processing cost, complexities associated with fabrication/thermo-mechanical processing conditions, problems associated with machining, and material wastage during conventional processing approaches [3-6]. The powder metallurgy (PM) processing approach, in general, has been found to be capable of addressing these issues very effectively. Several efforts have been made to prepare bulk titanium alloys via conventional PM technique, that is, cold compaction of elemental/pre-alloyed powders followed by their pressureless sintering (press-and-sinter method), in order to develop a technically simple and economically cost-effective near net-shape process $[7,8]$. However, high initial cost of pure titanium and pre-alloyed titanium powders, high reactivity of powders with the oxygen during various steps of fabrication processes, and poor 
mechanical properties due to porosity and chemical heterogeneity, have restricted the conventional press-and-sinter powder metallurgy approach to be exploited for various commercial purposes [7-11].

In recent years, an alternative powder metallurgy processing approach, based on mechanical alloying (MA) of elemental powders followed by their rapid sintering, such as spark plasma sintering, has been taken into account for synthesizing a wide variety of alloys with fine-grained microstructure and excellent mechanical properties [12-16]. Moreover, this approach was very effective in preparing complex alloy systems containing constituent alloying elements with a wide difference in their melting points, which are difficult to prepare through conventional liquid metallurgy routes. However, the problems of sticking of pure titanium powder with the vials and balls during milling and contamination due to the usage of process control agents still need to be resolved to make it a viable technique [17-19].

Recently, researchers have underlined the advantages of $\mathrm{TiH}_{2}$ powder as a precursor of titanium, due to significantly lower cost of titanium hydride powder as compared to that of the pure titanium powder [20]. Moreover, the use of extremely brittle $\mathrm{TiH}_{2}$ powder, instead of highly ductile pure titanium powder, can overcome the sticking/agglomeration issues as well as contamination-related issues by avoiding process control agents (PCAs) in the mechanical milling process. As a result, a uniform distribution of elemental powders with an almost complete powder yield can be ensured even a long time after mechanical alloying [21-23]. It has also been reported that various properties, such as grain refinement, improvement in superplastic forming and reduction in the flow stress, can be improved through temporary hydrogen alloying [24-30]. The ultrafine-grained titanium alloys are reported to exhibit superior properties, such as higher wear resistance and increased cell adhesion, as compared to their coarse-grained counterparts, owing to their high surface energy at the grain boundaries [29]. However, at the same time, negative effects of hydrogen on the mechanical properties of titanium alloys primarily manifest themselves in an embrittlement and decrease in ductility, including with cracking, due to hydride formation.

The influence of hydrogen on the properties of titanium alloys is a complex phenomenon, which depends on several factors, such as the content of hydrogen in the materials and volume fraction of the relevant phase, and so on. In general, the high hydrogen content in titanium alloys has detrimental effects on the mechanical properties. Therefore, particularly for the industrial use, the ASTM standard for titanium alloys requires the hydrogen concentration to be $<150 \mathrm{ppm}$. Due to the diffusion of hydrogen in titanium and titanium alloys, the hydrogen concentration can be reduced to a standard level by prolonged heat treatment in vacuum or under an inert atmosphere. Such processes, called "thermo hydrogen processing", have been investigated extensively for titanium alloys [31-34]. However, the prolonged dehydrogenation under vacuum/inert atmosphere is a complex and commercially uneconomical process.

The use of titanium hydride as a starting material or precursor of titanium in preparing titanium alloys, particularly $\beta$-phase stabilized titanium alloys, has not been thoroughly studied and it remains an important issue to produce $\beta$-phase stabilized titanium alloys with acceptable mechanical properties by using titanium hydride powder as a starting material. Therefore, the present work is focused on the development of a novel PM process to prepare $\beta$-phase stabilized titanium alloys by utilization of titanium hydride powder followed by two-step spark plasma sintering. The novel two-step spark plasma sintering process was developed by the present authors and it was successfully applied to prepare high-strength titanium from titanium hydride [35]. The newly developed two-step spark plasma sintering process is a rapid and efficient method, which can be utilized to prepare near net-shape titanium-based products using titanium-based commercially viable products. The two-step SPS (Spark Plasma Sintering) process is rapid and efficient in the sense that almost complete dehydrogenation can be achieved in a very short period of time, and both the steps of dehydrogenation and consolidation of powders are achieved under vacuum in a single loading of the powders without the necessity of removing the specimen after dehydrogenation and reloading it again. 
Therefore, the present work deals with the development of a PM process, based on the mechanical milling of a mixture of elemental powders followed two-step spark plasma sintering process, to prepare $\beta$-phase stabilized titanium-based alloys by using a mixture of titanium and titanium hydride powders as a starting powder. Since niobium acts as a strong $\beta$-phase stabilizer and titanium with 40 mass $\%$ niobium (that is, $\mathrm{Ti}: \mathrm{Nb}$ in 3:2 ratio) can retain the $\beta$ phase at low temperatures [36], an attempt has been made to prepare binary Ti- 40 mass $\% \mathrm{Nb}$ alloy, having a composition in the range of stable $\beta$ phase, in the present work. The proposed maneuvering method illustrates the feasibility of the two-step spark plasma sintering approach to prepare cost-effective $\beta$-titanium alloys directly using titanium hydride powder. In principle, the proposed powder metallurgy route is based on mechanical alloying of titanium hydride powder with the elemental titanium and niobium powder mixtures, followed by their dehydrogenation under vacuum conditions and subsequent compaction via the spark plasma sintering method. The effect of the amount of titanium hydride powder, used with the pure elemental titanium and niobium powders, during mechanical alloying and their effects after compaction of mechanically alloyed powders has been investigated. In particular, the yield, morphology and characteristics of mechanically alloyed powders were evaluated. In addition to that, the phase, microstructure and mechanical properties of the bulk specimens, prepared by the spark plasma sintering of thus obtained mechanically alloyed powders, were also evaluated and the results are presented and discussed in detail.

\section{Materials and procedure}

\subsection{Starting Material}

The titanium hydride, pure $\mathrm{Ti}$ and pure $\mathrm{Nb}$ elemental powders were used as initial materials. Titanium hydride (45 $\mu \mathrm{m}$ pass, $\sim 99 \%$ pure) and niobium (45 $\mu \mathrm{m}$ pass, $\sim 99.9 \%$ pure) powders were acquired from Kojundo Chemical Laboratory Co. Ltd. (Saitama, Japan). The high-purity Ti powder called "TILOP" (45 $\mu \mathrm{m}$ pass, gas-atomized low-oxygen titanium powder) was supplied by Osaka Titanium Technologies Co. Ltd. (Hyōgo Prefecture, Japan). The morphologies of the as-received titanium hydride $\left(\mathrm{TiH}_{2}\right)$, pure titanium $(\mathrm{Ti})$ and pure niobium $(\mathrm{Nb})$ powders are presented in Figure $1 \mathrm{a}-\mathrm{c}$, respectively. The $\mathrm{TiH}_{2}$ and $\mathrm{Nb}$ powder particles exhibit the irregular shape morphology whereas high-purity titanium powder particles exhibit spherical shape morphology. All three powders contain both coarse and fine-sized particles. The particle size distribution analysis, using a laser diffraction particle size analyzer, was performed by Shimadzu (Kyoto, Japan), SALD-2300. As-received titanium hydride, pure $\mathrm{Ti}$ and pure $\mathrm{Nb}$ powders had a mean particle size of approximately $25 \mu \mathrm{m}$, $15 \mu \mathrm{m}$ and $20 \mu \mathrm{m}$, respectively. Clearly, all three powders had a comparable starting mean particle size.
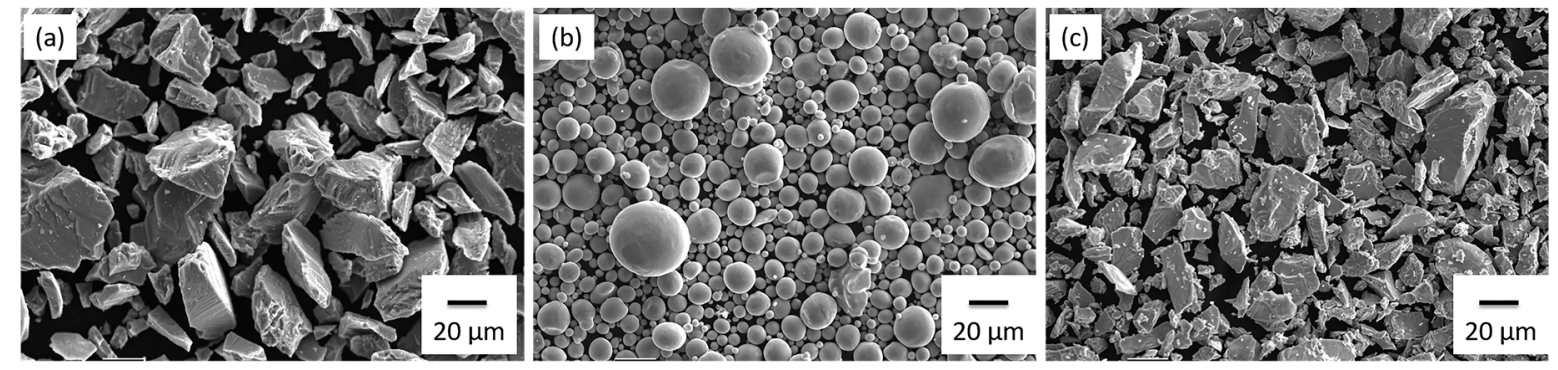

Figure 1. Morphology of as-received (a) titanium hydride, (b) pure titanium and (c) pure niobium powders.

\subsection{Mechanical Alloying}

To obtain a $\beta$-phase stabilized $\mathrm{Ti}-\mathrm{Nb}$ alloy, as-received $\mathrm{TiH}_{2}$ pure $\mathrm{Ti}$ and $\mathrm{Nb}$ powders were blended together according to the desired optimum stoichiometric composition, that is, $\sim 60$ mass $\%$ mixture of titanium and titanium hydride and $\sim 40$ mass $\% \mathrm{Nb}$ (further referred to as $\mathrm{Ti}-40 \mathrm{Nb}$ ). To study the effect of titanium hydride powder as a titanium source-cum-PCA, different amounts of 
titanium hydride were mixed with pure titanium and pure niobium powders, while maintaining the resultant amount of titanium and niobium in approximately 3:2 ratios.

Three different powder mixtures were prepared with varying relative amounts of pure titanium and titanium hydride powders. The composition and the identification of the powder mixtures are provided in Table 1. Subsequently, these blended powder mixtures were mechanically milled under argon atmosphere at room temperature using Fritsch P-5 planetary ball mill (Fritsch GmbH, Idar-Oberstein, Germany), with 500-mL vials and SUJ2 stainless steel balls, operating at a speed of $200 \mathrm{rpm}$. The ball-to-powder ratio was kept at 5:1. The blended powder mixtures were mechanically milled (MMed) for a total time period of $72 \mathrm{ks}$.

Table 1. Various compositions of the initial powder mixtures.

\begin{tabular}{cccc}
\hline \multirow{2}{*}{ Identification of Powder Mixtures } & \multicolumn{4}{c}{ Composition of Starting Powder Mixture (mass \%) } \\
\cline { 2 - 4 } & $\mathrm{TiH}_{\mathbf{2}}$ & Pure Ti & Pure Nb \\
\hline $\mathrm{Ti}-154$ & 10 & 50 & 40 \\
$\mathrm{Ti}-244$ & 20 & 40 & 40 \\
$\mathrm{Ti}-334$ & 30 & 30 & 40 \\
\hline
\end{tabular}

\subsection{Spark Plasma Sintering of Mechanically Alloyed Powders}

The mechanically alloyed powder was consolidated via spark plasma sintering (Dr. Sinter, Sumitomo Coal Mining Co. Ltd., Tokyo, Japan) in the high vacuum conditions $\left(\sim 10^{-3} \mathrm{~Pa}\right)$, using graphite die and punch. To minimize the amount of hydrogen content in the sample, the mechanically alloyed powders were dehydrogenated in SPS, without applying any external load, at $1073 \mathrm{~K}$ for $7.2 \mathrm{ks}$ under the high vacuum conditions. Subsequently, the dehydrogenated mechanically alloyed powders were sintered via spark plasma sintering method, at an applied external pressure of $50 \mathrm{MPa}$. To ensure high-density specimens, that is, without any appreciable amount of porosity during SPS process, the temperature and external pressure were programmed to rise, simultaneously, from room temperature to $1473 \mathrm{~K}$ and zero pressure to $50 \mathrm{MPa}$, respectively. Subsequently, the powder mass was held at maximum temperature and pressure conditions (at $1473 \mathrm{~K}$, and $50 \mathrm{MPa}$ ) for $1.8 \mathrm{ks}$, followed by furnace cooling up to room temperature. The temperature, during sintering process, was precisely measured by infrared camera. After SPS, disc-shaped specimens with dimensions $20 \mathrm{~mm}$ (diameter) $\times 4 \mathrm{~mm}$ (height) were obtained. The various sintering conditions used in this study are provided in Table 2.

Table 2. Spark plasma sintering conditions.

\begin{tabular}{cccccc}
\hline Steps & $\begin{array}{c}\text { SPS (Vacuum } \\
\text { Conditions) }\end{array}$ & $\begin{array}{c}\text { Heating/Cooling } \\
\text { Rate (K/min) }\end{array}$ & Temperature (K) & Pressure (MPa) & Holding Time \\
\hline Step-I & Dehydrogenation & 50 & 1073 & $\sim 0$ & $7.2 \mathrm{ks}$ \\
Step-II & Sintering & 100 & 1473 & 50 & $1.8 \mathrm{ks}$ \\
\hline
\end{tabular}

\subsection{Phase and Microstructure Analysis}

The various phases were analyzed by X-ray diffraction (XRD) method using CuK $\alpha(\lambda=1.5406 \AA)$ radiation. A scanning electron microscope (SEM) (Hitachi, Tokyo, Japan) equipped with back-scattered electron (BSE) and electron backscattered diffraction (EBSD) facilities was utilized to carried out the microstructural characterization of initial powders, mechanically alloyed powders, and sintered specimens (that is, Ti-154, Ti-244, and Ti-334 specimens). The primary elemental characterization was carried out by the energy dispersive X-ray spectroscopy (EDS) technique in SEM. 


\subsection{Mechanical Properties}

Vickers hardness measurements were performed on the cross-section of the samples, wherein the indentation were carried out under the load of $980.7 \mathrm{mN}$ (HV0.1) with dwelling time of $10 \mathrm{~s}$. The indentations were carried out randomly, wherein the distance between the indents was kept at least three times the size of the indent. An average of 20 indentations was considered as the representative hardness value of the test specimen. In addition, tensile tests were also performed at ambient temperature to evaluate the mechanical properties of the sintered specimens. The tensile tests were carried out at an initial strain rate of $5.6 \times 10^{-4} \mathrm{~s}^{-1}$ using an individual specimen with gauge dimensions of $3 \mathrm{~mm}$ (length), $1 \mathrm{~mm}$ (width), $1 \mathrm{~mm}$ (thickness). At least three samples were considered to calculate the average tensile properties of the specimens.

\section{Results and Discussion}

\subsection{Effect of Titanium Hydride on the Recovery of Mechanically Milled Powders}

The powder yield of Ti-154, Ti-244, and Ti-334 mechanically alloyed powder mixtures was approximately $\sim 63 \%, \sim 67 \%$ and $\sim 100 \%$, respectively. It reveals that increasing amount of titanium hydride powder leads to an increase in the yield of mechanically alloyed powder. It is interesting to note that an increment of titanium hydride, from 10 mass \% (that is, Ti-154) to 20 mass \% (that is, Ti-244), resulted in a relatively small amount of increment $(\sim 4 \%)$ in the yield, whereas an increment of titanium hydride up to 30 mass $\%$ resulted in approximately $100 \%$ powder yield. Such a trend of powder yield, together with visual observations, clearly suggests that the increasing amounts of titanium hydride successfully suppressed the agglomeration and sticking of powders with the balls and vials during milling, leading to an improved yield of mechanically alloyed powder.

\subsection{Morphology and Microstructure of Mechanically Milled Powders}

Figure 2 shows the morphology of the mechanically milled powder with varying amounts of titanium hydride. The powder particle size was measured from SEM micrographs. Several random particles were selected, and measured by ImageJ software. The mean size of those measured particles was considered as a representative particle size. The mean particle size of powder particles of Ti-154, Ti244 and Ti-334 mechanically alloyed powders is provided in Table 3. The powder particle size distribution of each mechanically alloyed powder is also shown in Figure 2. It can be observed that the morphology and particle size is significantly different in all three cases even though the milling was carried out for the same time period $(72 \mathrm{ks})$. Interestingly, the powder particle size for Ti-154 is significantly larger than that of Ti-244 and Ti-334 mechanically alloyed powders. Therefore, the results clearly suggest that there is a strong influence of the amount of titanium hydride on the morphology and particle size of the resulting powder during mechanical milling process. It can be clearly noted that the particle size of the resulting milled powder significantly decreases with increasing relative amount of titanium hydride powder in the mixture, and smallest powder particle size is obtained when the pure titanium and titanium hydride powders are in equal amounts in the starting mixture.

Figure 3 shows the SEM micrographs and elemental distribution maps of the Ti-154, Ti-244, and Ti-334 mechanically alloyed powders. As a general observation, it can be clearly noticed that the global distribution of titanium and niobium is uniform in all the milled powders. However, it would be worth pointing out that the Ti-154 mechanically alloyed powders demonstrated distinctively much finer elemental distribution as compared to Ti-244 and Ti-334 powders, wherein Ti-244 and Ti-334 mechanically alloyed powders clearly exhibited a distinguishably higher local concentration of elemental-component regions, that is, Ti-rich and $\mathrm{Nb}$-rich areas (Figure 3e-l). The chemical composition of powder particles was analyzed by EDS analysis, and the composition is shown in Table 4. It can be clearly noticed that all the powders have comparable compositions, lying in the beta-phase region. 


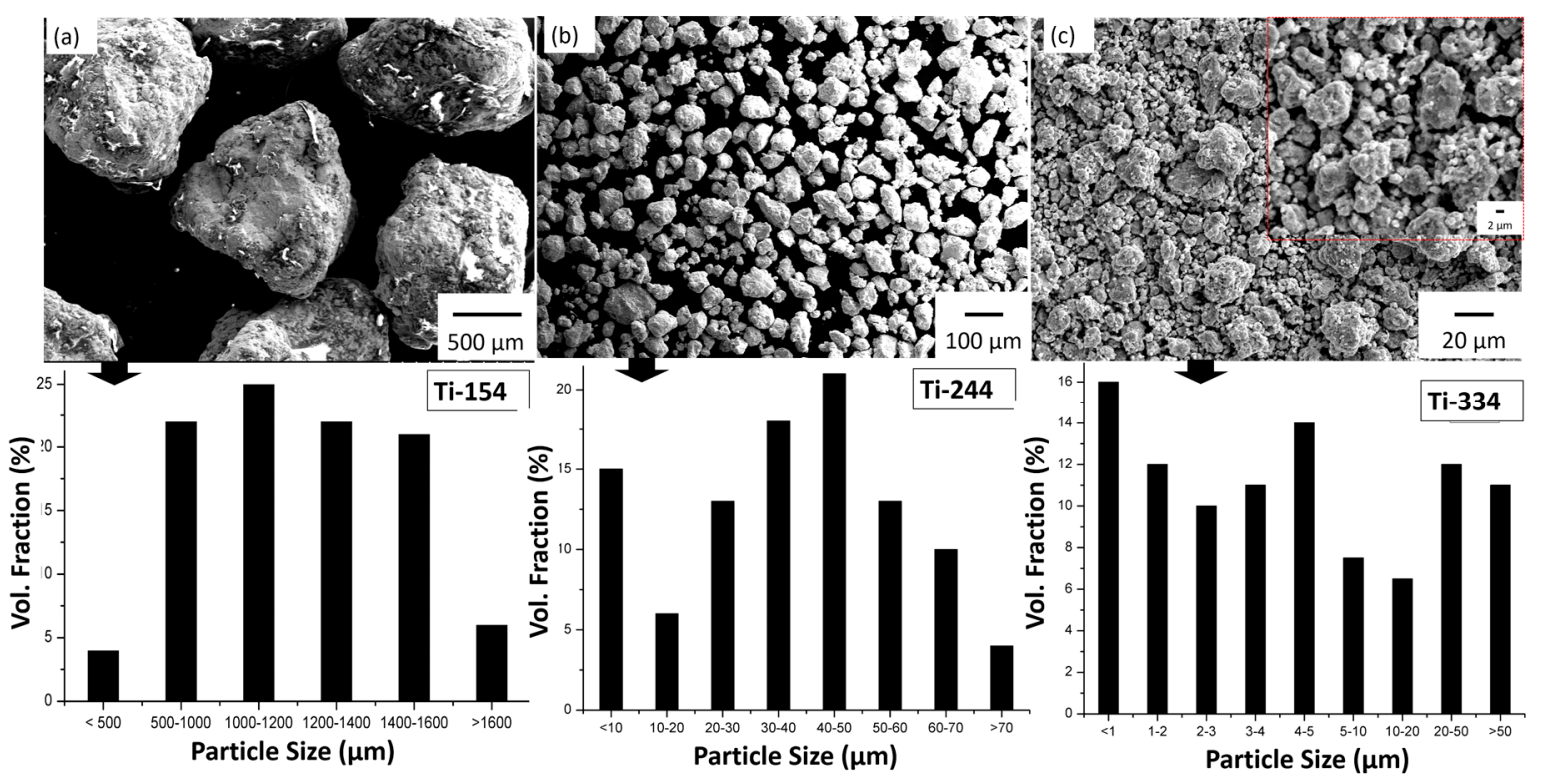

Figure 2. Morphology and particle size distribution of (a) Ti-154; (b) Ti-244; and (c) Ti-334 (magnified image is shown in inset) mechanically alloyed powders.

Table 3. The average particle size of the mechanically milled powders.

\begin{tabular}{cccc}
\hline Powders & $\begin{array}{c}\text { Ti-154 Mechanically } \\
\text { Alloyed Powder }\end{array}$ & $\begin{array}{c}\text { Ti-244 Mechanically } \\
\text { Alloyed Powder }\end{array}$ & $\begin{array}{c}\text { Ti-334 Mechanically } \\
\text { Alloyed Powder }\end{array}$ \\
\hline Mean particle size & $1000 \pm 270 \mu \mathrm{m}$ & $48 \pm 40 \mu \mathrm{m}$ & $4 \pm 2 \mu \mathrm{m}$ \\
\hline
\end{tabular}

Table 4. Overall average Chemical composition of mechanically alloyed powders.

\begin{tabular}{cccc}
\hline Powders & Ti-154 & Ti-244 & Ti-334 \\
\hline $\mathrm{Ti}($ mass \%) & $63.7( \pm 0.3)$ & $62.5( \pm 0.3)$ & $59.8( \pm 0.2)$ \\
$\mathrm{Nb}($ mass \%) & $36.3( \pm 0.2)$ & $37.5( \pm 0.2)$ & $40.2( \pm 0.2)$ \\
\hline
\end{tabular}

In order to understand the variation in morphology and elemental distribution in mechanically alloyed powders, high-magnification SEM imaging was carried out using secondary and back-scattered imaging modes. Figure 4 shows the micrographs of Ti-244 mechanically alloyed powder (that is, $\mathrm{Ti}-40 \mathrm{Nb}$ mechanically alloyed powder with $20 \% \mathrm{TiH}_{2}$ powder) particles, which is selected as a representative structure of the mechanically alloyed powders due to the fact that its composition and morphology lies in the transition region between the two extreme conditions. It can be clearly observed that the mechanical milling of Ti-244 powder mixture resulted in an apparently agglomerated powder particle with two distinct regions, that is, gray-colored phase and comparatively bright-colored phase. In particular, it can be clearly observed that the milled powder particles demonstrate layered structure wherein bright-colored particles are embedded in the relatively dark-colored matrix. From the BSE image, as shown in Figure $4 b$, the bright regions can be associated with heavier elements, that is, $\mathrm{Nb}$-rich regions, whereas dark-colored regions can be associated with light elements, that is, Ti-rich regions. Such a microstructural evolution can be associated with the combined effect of fragmentation of brittle hydride particles and plastic deformation of ductile elemental powders during the mechanical milling process. Similar microstructural evolution, associated with such types of brittle-ductile systems, was also reported by other researchers [37-39]. 


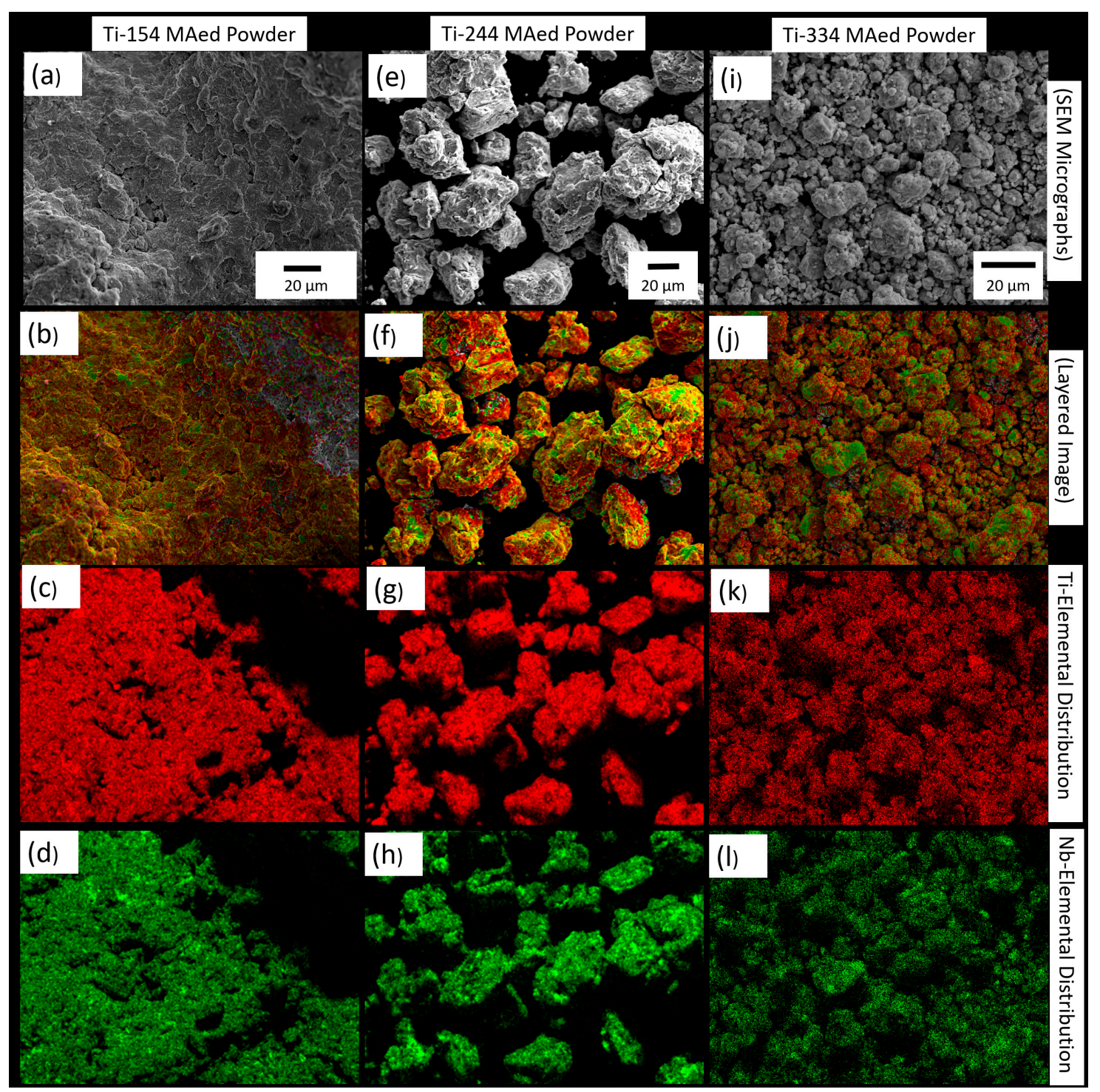

Figure 3. SEM micrographs with corresponding elemental distribution maps of Ti-154 (a-d); Ti-244 (e-h); and Ti-334 (i-1) mechanically alloyed (MAed) powders.

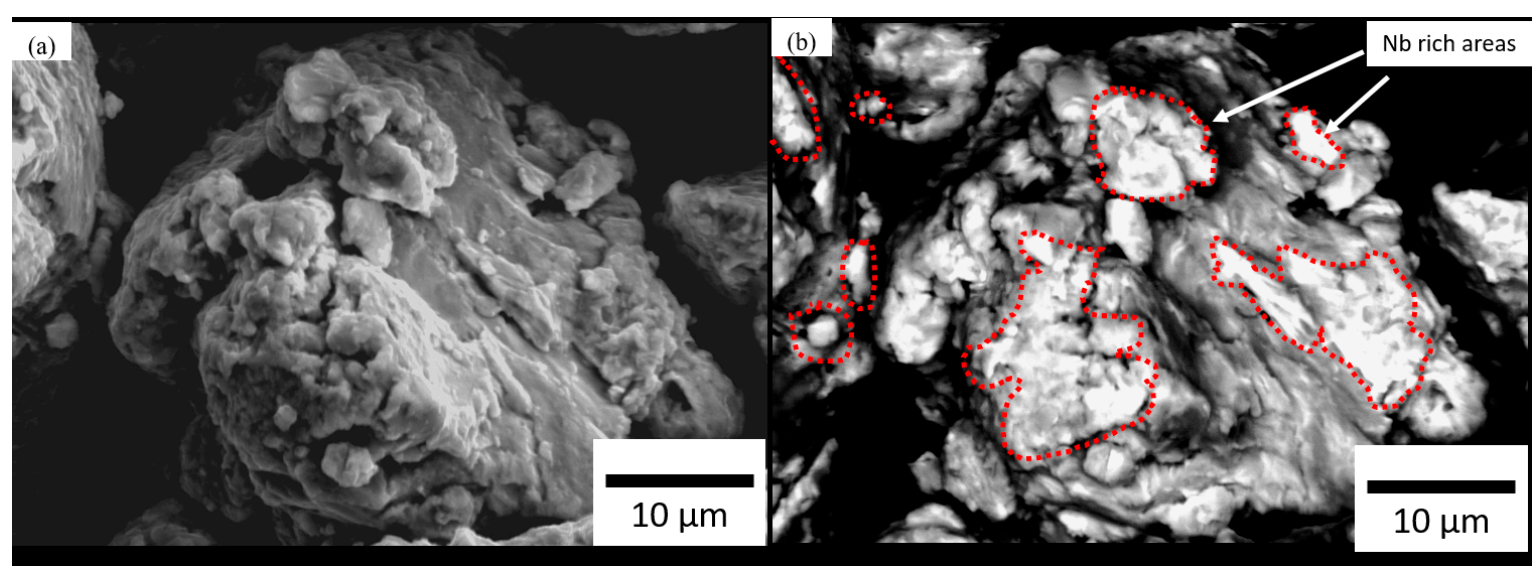

Figure 4. (a) Secondary Electron (SE), and (b) Backscattered Electron (BSE) micrograph of $72 \mathrm{ks}$ mechanically alloyed Ti-244 powder. 


\subsection{Microstructural Characteristics of Sintered $\mathrm{Ti}-\mathrm{Nb}$ Alloys}

Figure 5a presents the XRD profiles of the Ti-154, Ti-244 and Ti-334 sintered specimens. An indexing of the XRD profiles clearly indicated that spark plasma sintering of all the mechanically alloyed powders of Ti-154, Ti-244 and Ti-334 resulted in the formation of primarily the $\beta$ phase, together with a very small amounts of $\gamma$ phase. However, the XRD peaks corresponding to oxides or intermetallic phases were not found to be present in the XRD of Ti-154, Ti-244 and Ti-334 specimens.

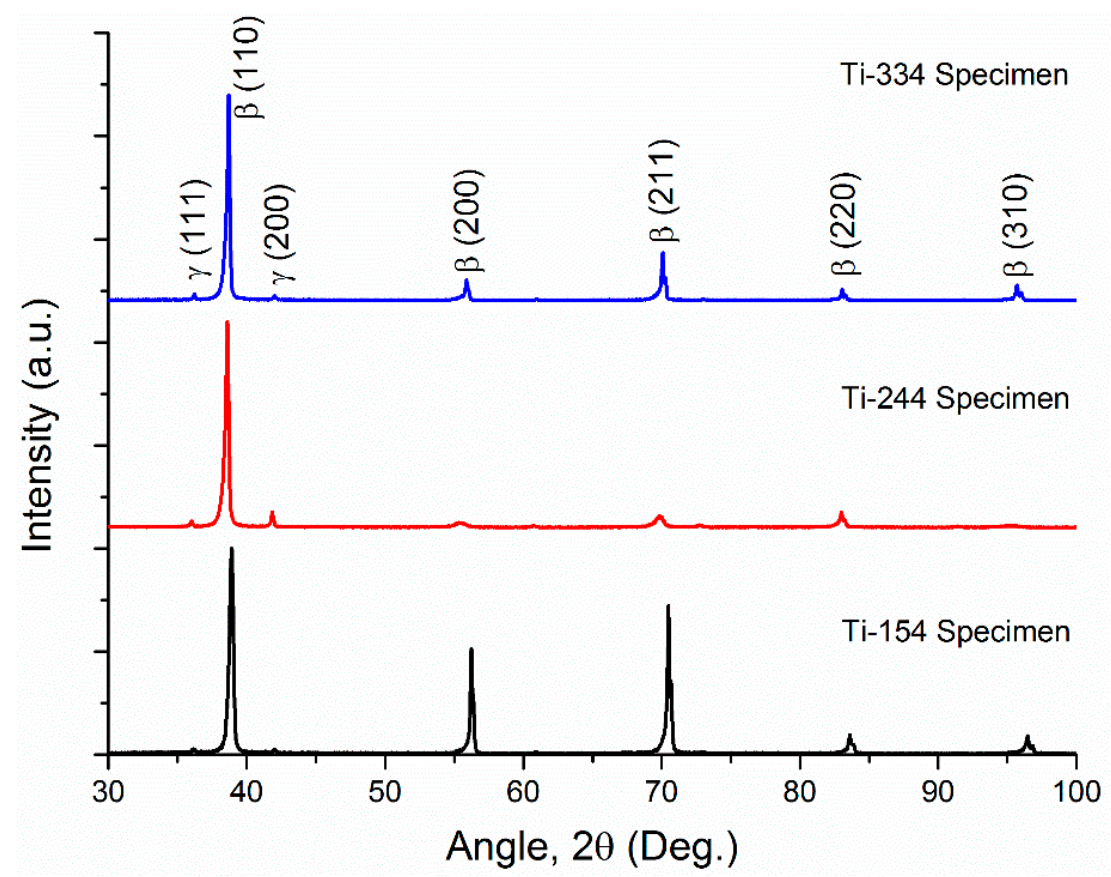

(a)

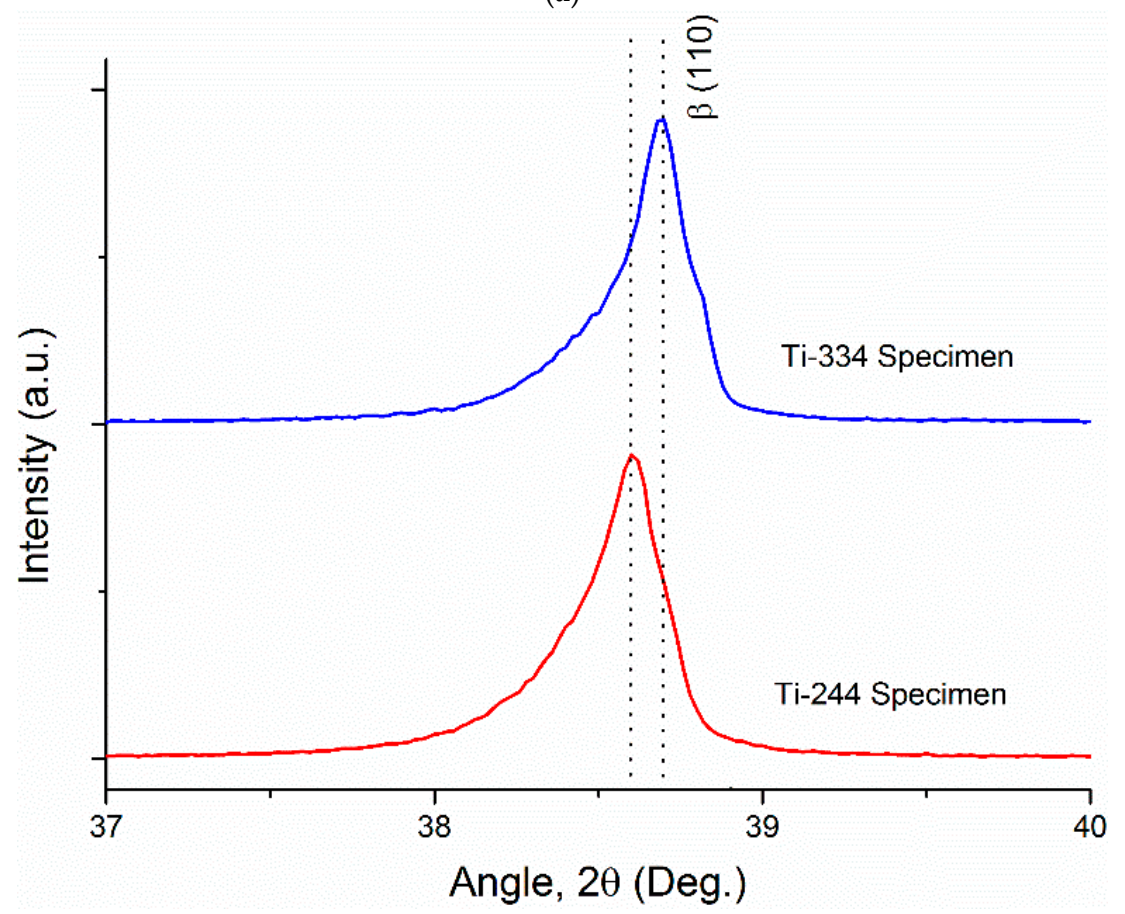

(b)

Figure 5. X-Ray Diffraction (XRD) of (a) Ti-154, Ti244 and Ti-334 specimens; (b) the relative peak shift of $\beta$ (110) peak position. 
In general, the $\gamma$ (face-centered tetragonal) phase is known to exist in the Ti-H system when hydrogen content is $1-3 \%$ and it is presumably isomorphic with the metastable $\gamma-\mathrm{ZrH}$ in the $\mathrm{Zr}-\mathrm{H}$ system $[40,41]$. The recently assessed phase diagram for the Ti-H system clearly shows that $\gamma$-hydrides are precipitated in $\alpha$-titanium during cooling below $443 \mathrm{~K}$ through a periodic reaction $(\gamma \leftrightarrow \alpha+\delta)$ [42]. The $\gamma$-hydride is considered as a metastable phase of the stoichiometric TiH composition with ordered hydrogen atoms, and is preferably generated under conditions of lower hydrogen concentrations.

An analysis of Figure 5a also shows that the relative intensity of the $\gamma$ phase is largest in the Ti-244 specimen, indicating that the hydrogen retention in Ti-244 is large as compared to both Ti-151 and Ti-334 specimens. Interestingly, in spite of utilizing higher amount of titanium hydride, the relative peak intensity of the $\gamma$ phase is very low for the Ti-334 specimen as compared to that of the Ti-244 specimen. The higher hydrogen retention in Ti-244 can be attributed to the large particle size as compared to the Ti-334 specimen, which decreases the powder particle surface area and leads to comparably less effective dehydrogenation [43].

A careful comparison between the bulk specimens of Ti-244 and Ti334 also demonstrates the relative shift of the peak positions of the $\beta$ phase, as shown in Figure $5 \mathrm{~b}$. Such a shifting of XRD peaks can be attributed to the lattice expansion due to higher hydrogen retention. In general, if the hydrogen atoms occupy the octahedral interstitials, the body-centered cubic (bcc) lattice may expand, which results in the shifting of peaks towards the lower $2 \theta$ angles [44]. The lattice parameters of the XRD peak corresponding to (110) $\beta$ phase were calculated for Ti-244 and Ti-334 specimens; this led to the values of $a=0.3296 \mathrm{~nm}$ and $0.3289 \mathrm{~nm}$, respectively. The calculated lattice parameter of bcc $\beta$ phase is in good agreement with the results presented in other studies [45-47].

Figure 6 shows SEM micrographs, together with elemental distribution maps, illustrating the microstructure of Ti-154, Ti-244 and Ti-334 specimens. In general, it can be observed that the microstructure (BSE-SEM image with elemental distribution maps) of all the Ti-Nb specimens reveals the presence of two phases: (i) gray-colored phase with equiaxed grains as a major phase, consisting of uniform distribution of $\mathrm{Ti}$ and $\mathrm{Nb}$; and (ii) a relatively darker phase with plate-like morphology, uniformly distributed in the matrix, consisting of relatively higher Ti content and relatively lower $\mathrm{Nb}$ content as compared to the matrix. The chemical composition of these phases was analyzed by EDS point analysis. The point analysis revealed that the darker phase, that is, precipitates, consisted of $\mathrm{Ti}$ and $\mathrm{Nb}$ in the ratio of approximately $4: 1(\mathrm{Ti}=78.8$ mass $\%$ and $\mathrm{Nb}=21.2$ mass $\%)$. On the other hand, the gray-colored phase consisted of $\mathrm{Ti}$ and $\mathrm{Nb}$ in the ratio of approximately 3:2 $(\mathrm{Ti}=59.4$ mass $\%$ and $\mathrm{Nb}=40$ mass \%. Furthermore, an EDS line analysis was also carried out at the local regions, as shown in Figure 6d, which shows that the dark-colored precipitates are titanium rich whereas the gray-colored matrix is the balanced mixture of Ti and $\mathrm{Nb}$ elements. Therefore, the gray-colored phase can be identified as the $\beta$ phase, whereas the darker phase can be identified as relative lighter $\mathrm{TiNb}$ precipitates, possibly some hydride precipitates. The quantitative evaluation of the phases was carried out by image analysis method using ImageJ. At least 20 micrographs were considered for the image analysis. The mean volume fractions of the precipitates in Ti-154 and Ti-244 specimens were found to be approximately $\sim 7.2 \%$ and $13.85 \%$, respectively. The volume fraction of precipitates for Ti-334 was approximately $\sim 6.3 \%$, which is relatively low as compared to that of Ti-154 and Ti-244 specimens. 


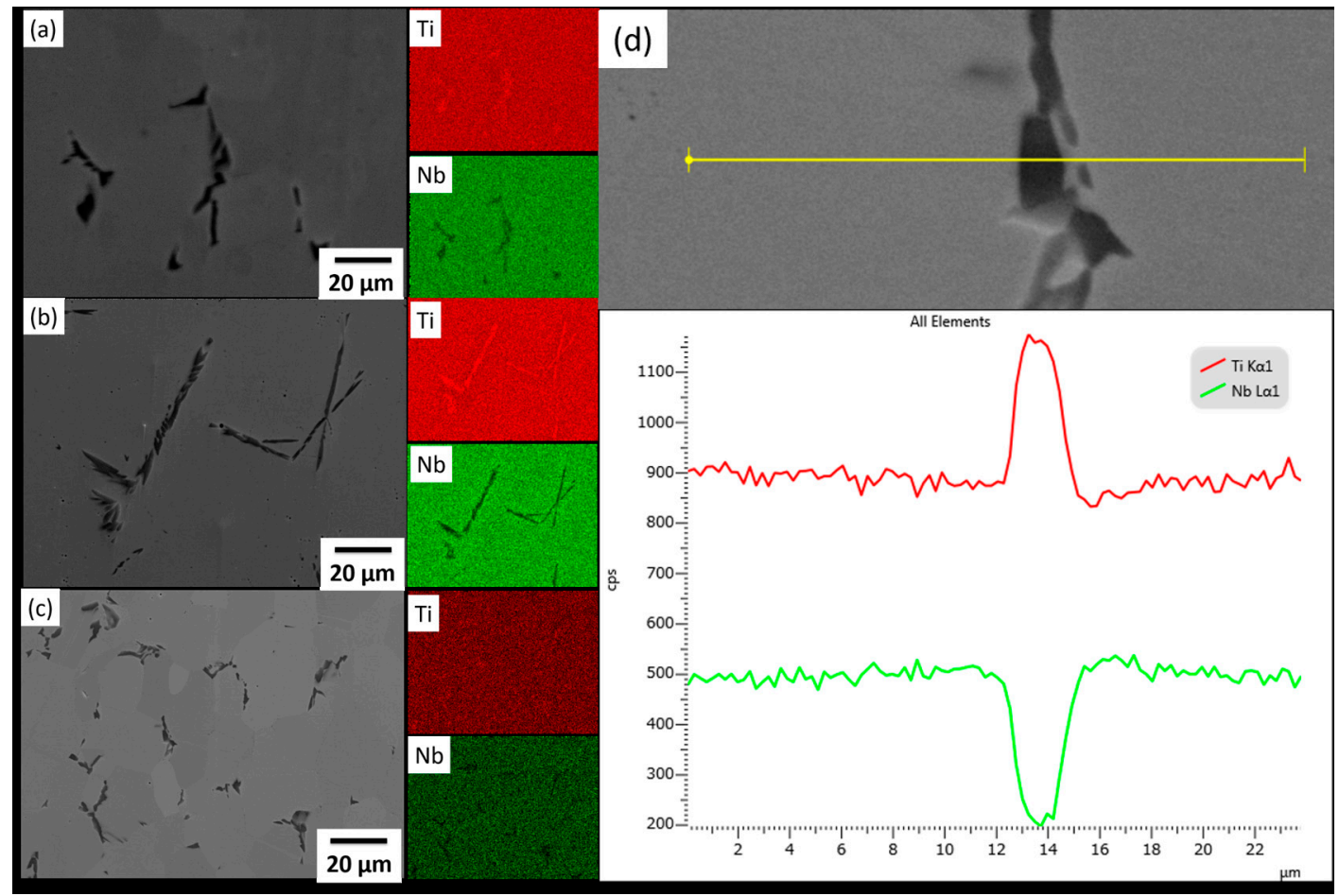

Figure 6. Typical SEM micrographs of (a) Ti-154; (b) Ti-244; (c) Ti-334 specimens with their Energy-dispersive X-ray spectroscopy (EDS) elemental mappings; and (d) line analysis of Ti-334 specimen.

The microstructure and grain size distribution was also studied by EBSD analysis, and the EBSD maps of Ti-154, Ti-244 and Ti-334 specimens are presented in Figure 7. It can be clearly observed that the sintered compacts of Ti-154 alloy consisted of coarse-grained structure with equiaxed $\beta$-phase grains of average size more than $1 \mathrm{~mm}$, as calculated using a linear intercept method. On the other hand, the sintered compacts of Ti-244 alloy demonstrated the presence of equiaxed grains with more or less bimodal grain size distribution, consisting of very small grains of the size on the order of $\sim 1-10 \mu \mathrm{m}$ and comparatively very coarse grains of size on the order of $\sim 150-200 \mu \mathrm{m}$ (Figure $7 \mathrm{~b}$ ). It would be worth pointing out that the fine-grained and coarse-grained areas are heterogeneously distributed in this case. Finally, the microstructure of sintered compacts of Ti-334 alloy indicated that the matrix contains uniformly distributed fine and coarse grains, wherein the fine grains on the order of 1-5 $\mu \mathrm{m}$ and comparatively coarse grains of the order of 30-50 $\mu \mathrm{m}$ are present in the microstructure (Figure $7 \mathrm{c}$ ). The average size of $\beta$ grains, for the Ti-334 specimen, is approximately13 $\mu \mathrm{m}$ (Figure 7c).

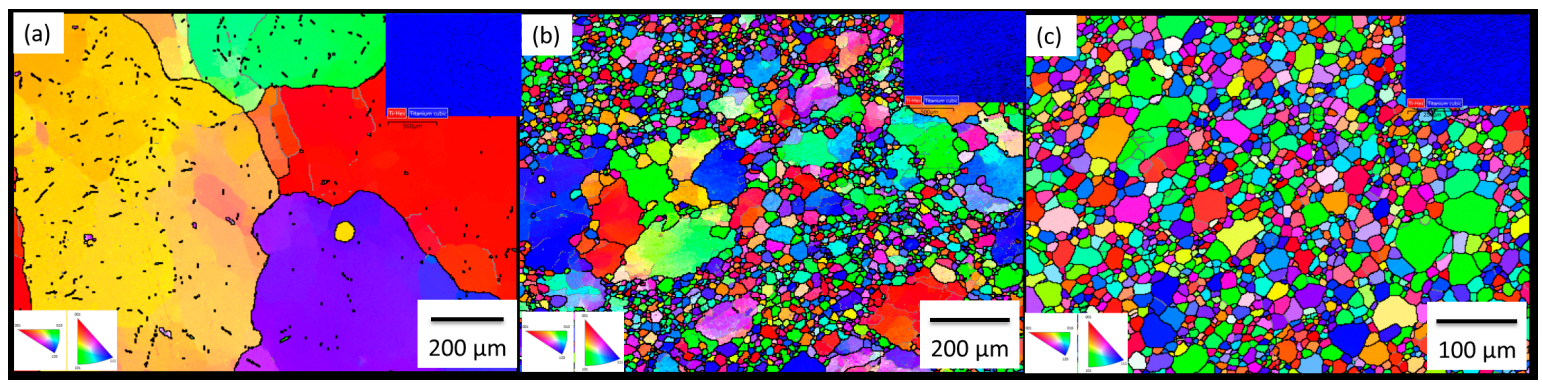

Figure 7. Electron backscatter diffraction (EBSD) maps of (a) Ti-154; (b) Ti-244; and (c) Ti334 specimens (the phase maps are shown in the inset). 


\subsection{Mechanical Properties of Bulk Ti-40Nb Alloys}

The average hardness of sintered specimens was estimated by Vickers hardness measurements, wherein average hardness was calculated using 20 measurements on each specimen. The microhardness values (Hv) of the bulk Ti-154, Ti-244 and Ti334 specimens are shown in Figure 8. It can be seen that the average hardness increased with increasing amounts of titanium hydride in the starting powder mixture. However, it is interesting to note that the average hardness increased only slightly from Ti-154 to Ti-244 specimens, whereas the average hardness increased significantly in case of the Ti-334 alloy. In general, the hardness can be associated with the various possible factors such as relative density, amount of hydrogen retention in the bulk specimen, and the average grain size of the bulk specimen [48]. Since the compaction of bulk specimens of Ti-154, Ti-244 and Ti-334 was performed under identical dehydrogenation and sintering conditions, the possible reason of high/low hardness values due to low/high hydrogen retention may not be considered as a major factor for variation in the average hardness values. Since the hardness increases more significantly with decreasing grain size, the increasing microhardness values of the specimens can be attributed primarily to the decreasing average grain size, that is, microstructural refinement.

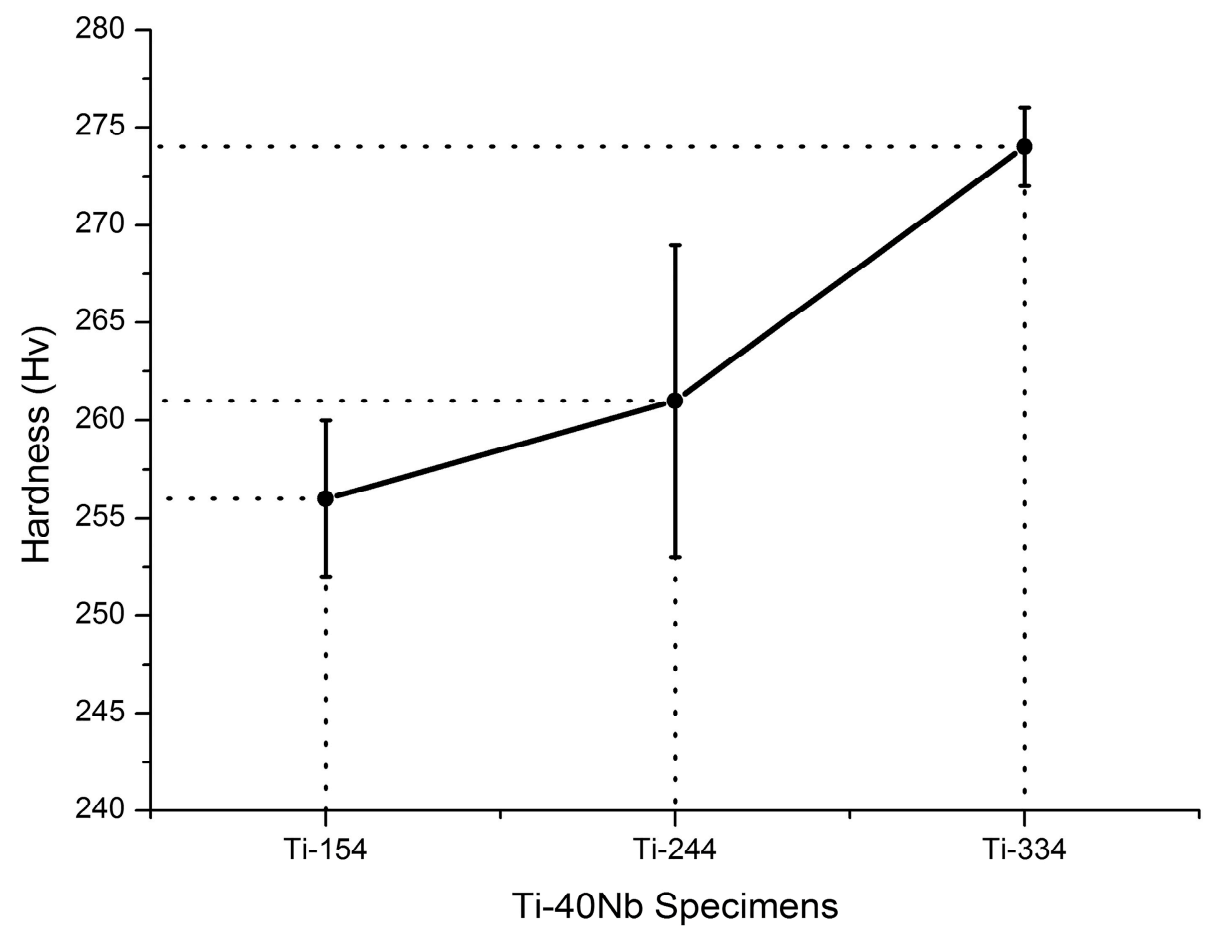

Figure 8. Vickers hardness of Ti-154, Ti-244 and Ti-334 specimens.

It can also be noticed that the standard deviation from the mean hardness value is significantly different for all the three types of specimens. Such a variation in the standard deviation from the mean value of hardness of each specimen can also be associated with the grain size. It was observed that the Ti-154 specimens had homogeneous and coarse-grained structures consisting of equiaxed grains of size approximately $1 \mathrm{~mm}$, which is considerably larger as compared to that of the Ti-244 $(19.5 \mu \mathrm{m})$ and Ti-334 $(13 \mu \mathrm{m})$ specimens (Figure 7). As a result, the average hardness value of Ti-154 is lowest and the standard deviation from the mean value is very small for the Ti-154 specimen. Following similar arguments, the low hardness values and large standard deviation from the mean value for the Ti-244 specimen can be associated with the heterogeneous bimodal microstructure, that is, effect of large grains $(\sim 150-200 \mu \mathrm{m})$ and comparatively very small grains $(\sim 1-10 \mu \mathrm{m})$. The average grain size for the Ti-334 specimen is smallest $(\sim 13 \mu \mathrm{m})$ and the microstructure is also equiaxed and uniform. Hence, 
the high hardness value with low standard deviation can be expected for the Ti-334 specimen. It is well known that the hardness is proportional to the yield stress of an engineering structural material [49]. However, surface hardness analysis is only a preliminary examination to analyze materials' mechanical properties. Therefore, further tensile tests and fracture surface analysis of broken tensile specimens were carried out to explain more about mechanical properties of each $\mathrm{Ti}-40 \mathrm{Nb}$ specimen.

Figure 9 shows the representative nominal stress-strain curves for each $\mathrm{Ti}-40 \mathrm{Nb}$ specimen, that is, Ti-154, Ti-244 and Ti-334 specimens. It can be observed that the Ti-154 specimen elastically deforms up to approximately $450 \mathrm{MPa}$ but then suddenly fails without showing any plastic deformation. On the other hand, it can be observed that the Ti-334 samples elastically deform up to approximately $775 \mathrm{MPa}$ and then start to deform plastically up to $18 \%$, whereas the Ti-244 specimen deforms elastically up to approximately $755 \mathrm{MPa}$ and then starts to deform plastically up to $4 \%$, and then suddenly fails. These results suggest that both Ti-334 and Ti-244 specimens share almost similar elastic behavior, but their plastic deformation behaviors are significantly different. The higher strength of the Ti-334 specimen is expected to be due to the finer grain size and uniform microstructure. In addition, the Ti-334 specimen consisted of fine grains and homogeneous bimodal microstructure, including fine precipitates. Therefore, dispersion strengthening because of the precipitates may have resulted in higher yield stress in Ti-334 and Ti-244. The higher ductility of Ti-334 can also be attributed to the homogeneous bimodal microstructure in comparison to Ti-244 specimens, which consisted of heterogeneous bimodal structures.
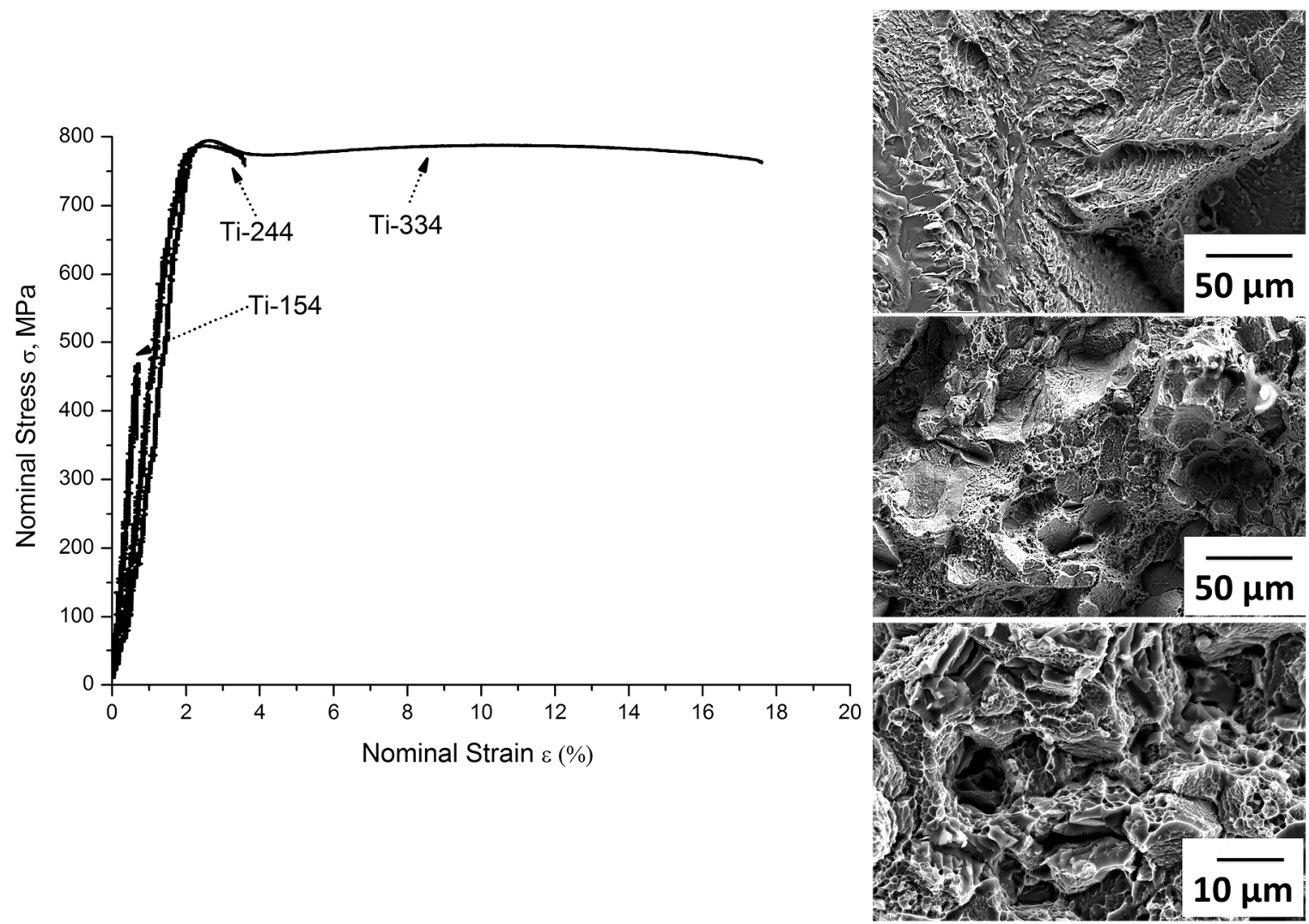

Figure 9. Representative engineering stress-strain curves and SEM micrographs of respective tensile fractographs of Ti-154, Ti-244 and Ti-334 specimens.

The morphology of the fracture surface of all the specimens was also analyzed after the tensile testing to understand the fracture behavior of the sintered specimens. The fractured surfaces of the investigated $\mathrm{Ti}-\mathrm{Nb}$ alloy, processed with different titanium hydride contents, are shown in Figure 9, together with their respective stress-strain curves. The fracture surface of the Ti-154 specimen is 
relatively featureless with flat transgranular facets and some surface steps, indicating the brittle fracture. It can be seen that the Ti-334 specimen shows the typical ductile nature of failure with fine microvoids across the entire surface. The mixed fracture surface, consisting of transgranular and intergranular dimpled fractures with cleavage fracture components, was observed for the Ti-244 specimen. Such a variation in the fracture could be attributed to the variation in grain size and size distribution, together with a slight variation in retained hydrogen in the specimens [50].

A comparison of the mechanical properties of $\mathrm{Ti}-40 \mathrm{Nb}$ alloys prepared through various processes is presented in Table 5. It can be observed that the Ti-334 alloy, prepared in the present study, exhibited the best combination of strength and ductility as reported in the literature for the same composition prepared by other methods.

Table 5. Mechanical properties of $\mathrm{Ti}-\mathrm{Nb}$ alloys processed by various conditions.

\begin{tabular}{|c|c|c|c|c|c|}
\hline Data & $\begin{array}{l}\text { Yield Strength } \\
(\mathrm{MPa})\end{array}$ & UTS (MPa) & Strain $(\%)$ & $\begin{array}{l}\text { Young's } \\
\text { Modulus (GPa) }\end{array}$ & Ref. \\
\hline $\begin{array}{l}\text { Ti-26 at \% Nb [Solution-treatment + aged at } \\
200 \text { to } 873 \mathrm{~K} \text { for } 3.6 \mathrm{ks} \text { ] }\end{array}$ & $\sim 100-120$ & $\sim 350-520$ & $\sim 8-10$ & - & [45] \\
\hline $\mathrm{Ti}-26$ at $\% \mathrm{Nb}$ & $\sim 600$ & $\sim 620$ & 13 & $\sim 60$ & [51] \\
\hline $\mathrm{Ti}-22$ at $\% \mathrm{Nb}$ [as sintered] & $\sim 649$ & $\sim 754$ & 1.43 & $\sim 71$ & [52] \\
\hline $\mathrm{Ti}-26$ at $\% \mathrm{Nb}$ [ST at $1173 \mathrm{~K}$ for $1.8 \mathrm{ks}$ ] & $\sim 180$ & $\sim 420$ & 17 & - & [53] \\
\hline $\mathrm{Ti}-30$ at $\% \mathrm{Nb}$ (cold rolled + ST $1123 \mathrm{~K})$ & $\sim 411$ & $\sim 493$ & 21.1 & 45 & \\
\hline Ti-30 at \% Nb (cold rolled + ST $1223 \mathrm{~K})$ & $\sim 541$ & $\sim 587$ & 17.1 & 57 & \\
\hline $\begin{array}{c}\text { Ti-334, } \\
\text { that is, } \mathrm{Ti}-40 \text { mass } \% \mathrm{Nb} \text { or }(\mathrm{Ti}-26 \text { at. } \% \mathrm{Nb})\end{array}$ & $\sim 760 \pm 3$ & $\sim 775 \pm 3$ & $16.5 \pm 1$ & - & Present work \\
\hline $\begin{array}{l}\text { Ti-244, } \\
\text { that is, } \mathrm{Ti}-40 \text { mass } \% \mathrm{Nb} \text { or }(\mathrm{Ti}-26 \text { at. } \% \mathrm{Nb})\end{array}$ & $\sim 750 \pm 7$ & $\sim 755 \pm 12$ & $4 \pm 2$ & - & Present work \\
\hline
\end{tabular}

\section{Conclusions}

The $\beta-\mathrm{Ti}-40 \mathrm{Nb}$ (mass \%) alloy was successfully prepared by mechanical milling of a mixture of pure $\mathrm{Ti}$, pure $\mathrm{Nb}$, and Ti hydride powders, utilizing titanium hydride powder as a Ti precursor as well as process control agent, followed by a two-step spark plasma sintering method. An investigation was carried out on the role of titanium hydride powder, during its mechanical alloying with elemental titanium and niobium powders, and further impacts on the microstructural and mechanical properties of Ti-40Nb alloy were discussed.

The mechanical alloying of elemental $\mathrm{Ti}$ and $\mathrm{Nb}$ powders was performed with different amounts of titanium hydride. The results show that the powder yield increases and resultant powder particle size decreases with increasing content of titanium hydride. The milled powders were dehydrogenated and sintered simultaneously, using spark plasma sintering. The microstructure and mechanical properties of the specimens were analyzed. All of the sintered compacts exhibited equiaxed microstructure with primarily $\beta$ phase, wherein sintered compacts with 10 mass \% titanium hydride exhibited coarse-grained structures, whereas sintered compacts with 20 and 30 mass \% titanium hydride resulted in fine-grained bimodal structures. The results also suggested that an increasing amount of titanium hydride leads to not only the finer-grained bimodal structure but also the spatial distribution of fine/coarse grains changed from heterogeneous to homogeneous in nature. Amongst the fabricated specimens, Ti-40Nb compact processed with the highest amount of titanium hydride (Ti-334) exhibited highest strength $(\sim 775 \mathrm{MPa})$ and ductility $(\sim 16.5 \%)$ under tensile tests. The highest strength of the Ti-334 specimen was associated with the finer grain size and uniform microstructure. This study provides a new understanding of cost-effective powder metallurgy processing of $\mathrm{Ti}-\mathrm{Nb}$ alloys for commercial applications. 
Author Contributions: B.S. has fabricated the specimens, and analyzed the experimental data. S.K.V. modified the manuscript. All authors contributed to the discussion for the manuscript, and approved the final version.

Funding: This research received no external funding.

Conflicts of Interest: The authors declare no conflict of interest.

\section{References}

1. Weiss, I.; Semiatin, S.L. Thermomechanical processing of beta titanium alloys-An overview. Mater. Sci. Eng. A 1998, 243, 46-65. [CrossRef]

2. Donachie, M.J., Jr. Titanium: A Technical Guide, 2nd ed.; ASM International: Materials Park, OH, USA, 2000; ISBN 0-87170-686-5, SAN 204-7586.

3. Froes, F.H.; Gungor, M.N.; Imam, M.A. Cost-affordable titanium: The component fabrication perspective. J. Min. Met. Mater. Soc. 2007, 59, 28-31. [CrossRef]

4. Veiga, C.; Davim, J.P.; Loureiro, A. Properties and applications of titanium alloys: A brief review. Rev. Adv. Mater. Sci. 2012, 32, 133-148.

5. Imam, M.A.; Froes, F.H. Low cost titanium and developing applications. JOM 2010, 62, 17-20. [CrossRef]

6. Boyer, R.R. An overview on the use of titanium in the aerospace industry. Mater. Sci. Eng. A 1996, 213, 103-114. [CrossRef]

7. Froes, F.H.; Tacoma, W. Titanium Powder Metallurgy: A review-Part 1. Adv. Mater. Process. 2012, 170, 16-22.

8. Qian, M.; Yang, Y.F.; Luo, S.D.; Tang, H.P. Titanium Powder Metallurgy, 1st ed.; Qian, M., Froes, F.H., Eds.; Elsevier: Cambridge, MA, USA, 2015; pp. 201-218, ISBN 978-0-12-800054-0.

9. Bolzoni, L.; Ruiz-Navas, E.M.; Gordo, E. Powder metallurgy CP-Ti performances: Hydride-dehydride vs. Sponge. Mater. Des. 2014, 60, 226-232. [CrossRef]

10. Fang, Z.Z.; Paramore, J.D.; Sun, P.; Chandran, K.S.R.; Zhang, Y.; Xia, Y.; Cao, F.; Koopman, M.; Free, M. Powder metallurgy of titanium-Past, present, and future. Int. Mater. Rev. 2017. [CrossRef]

11. Ivasishin, O.; Moxso, V. Low-cost titanium hydride powder metallurgy. Titanium Powder Metallurgy; Elsevier: Cambridge, MA, USA, 2015; pp. 117-148, ISBN 978-0-12-800054-0. [CrossRef]

12. Gilman, P.S.; Benjamin, J.S. Mechanical Alloying. Annu. Rev. Mater. Sci. 1983, 13, 279-300. [CrossRef]

13. Suryanarayana, C. Synthesis of nanocomposites by mechanical alloying. J. Alloys Compd. 2011, 509, S229-S234. [CrossRef]

14. Terayama, A.; Fuyama, F.; Yamashita, Y.; Ishizaki, I.; Kyogoku, H. Fabrication of Ti-Nb alloys by powder metallurgy process and their shape memory characteristics. J. Alloys Compd. 2013, 577, S408-S412. [CrossRef]

15. Shang, C.; Bououdina, M.; Guo, Z.X. Structural stability and dehydrogenation of $\left(\mathrm{MgH}_{2}+\mathrm{Al}, \mathrm{Nb}\right) \mathrm{Powder}$ mixtures during mechanical alloying. Mater. Trans. 2003, 44, 2356-2362. [CrossRef]

16. Huot, J.; Pelletier, J.F.; Liang, G.; Sutton, M.; Schulz, R. Structure of nanocomposite metal hydrides. J. Alloys Compd. 2002, 330-332, 727-731. [CrossRef]

17. Zhuravleva, K.; Bonisch, M.; Scudino, S.; Calin, M.; Schultz, L.; Eckert, J.; Gebert, A. Phase transformations in ball-milled Ti-40Nb and Ti-45Nb powders upon quenching from the $\beta$-phase region. Powder Technol. 2014, 253, 166-171. [CrossRef]

18. Zhuravleva, K.; Scudino, S.; Khboshkhoo, M.S.; Gebert, A.; Calin, M.; Schultz, L.; Eckert, J. Mechanical alloying of $\beta$-type Ti-Nb for biomedical applications. Adv. Eng. Mater. 2013, 15, 262-268. [CrossRef]

19. Nouri, A.; Hodgson, P.D.; Wen, C. Effect of ball-milling time on the structural characteristics of biomedical porous Ti-Sn-Nb alloy. Mater. Sci. Eng. C 2011, 31, 921-928. [CrossRef]

20. Lavender, C.A.; Moxson, V.S.; Duz, V.A. Cost-Effective Production of Powder Metallurgy Titanium Components for High-Volume Commercial Applications; U.S. Department of Energy under Contract DE-AC05-76RL01830, PNNL-19932: Oak Ridge, TN, USA, October 2010; pp. 1-5.

21. Sharma, B.; Vajpai, S.K.; Ameyama, K. Microstructure and properties of beta Ti-Nb alloy prepared by powder metallurgy route using titanium hydride powder. J. Alloys Compd. 2016, 656, 978-986. [CrossRef]

22. Sharma, B.; Vajpai, S.K.; Ameyama, K. Synthesis of ternary Ti-25Nb-11Sn alloy by powder metallurgy route using titanium hydride powder. J. Mater. Trans. 2016, 57, 1440-1446. [CrossRef]

23. Li, Y.H.; Chen, R.B.; Qi, G.X.; Wang, Z.T.; Deng, Z.Y. Powder sintering of porous Ti-15Mo alloy from TiH and Mo powders. J. Alloys Compd. 2009, 485, 215-218. [CrossRef] 
24. Froes, F.H.; Senkov, O.N.; Qazi, J.I. Hydrogen as a temporary alloying element in titanium alloys: Thermohydrogen processing. Int. Mater. Rev. 2004, 49, 227-245. [CrossRef]

25. Nakahigashi, J.; Yoshimura, H. Ultra-fine grain refinement and tensile properties of titanium alloys obtained through protium treatment. J. Alloys Compd. 2002, 330-332, 384-388. [CrossRef]

26. Fang, Z.Z.; Sun, P.; Wang, H. Hydrogen sintering of titanium to produce high density fine grain titanium alloys. Adv. Eng. Mater. 2012, 14, 383-387. [CrossRef]

27. Yoshimura, H.; Kimura, K.; Hayashi, M.; Ishii, M.; Hanamura, T.; Takamura, J.-I. Ultrafine equiaxed grain refinement and improvement of mechanical properties of $\alpha+\beta$ type titanium alloys by hydrogenation, hot working, heat treatment, and dehydrogenation. J. Mater. Trans. JIM 1994, 35, 266-272. [CrossRef]

28. Kerr, W.R. The effect of hydrogen as a temporary alloying element on the microstructure and tensile properties of Ti-6Al-4V. Metall. Trans. A 1985, 16, 1077-1087. [CrossRef]

29. Park, J.-W.; Kim, Y.J.; Park, C.H.; Lee, D.H.; Ko, Y.G.; Jang, J.H.; Lee, C.S. Enhanced osteoblast response to an equal channel angular pressing-processed pure titanium substrate with microrough surface topography. Acta Biomater. 2009, 5, 3272-3280. [CrossRef] [PubMed]

30. Kolachev, B.A. Hydrogen in metals and alloys. Met. Sci. Heat Treat. 1999, 41, 93-100. [CrossRef]

31. Macin, V.; Christ, H.-J. Influence of hydride-induced microstructure modification on mechanical properties of metastable beta titanium alloy Ti-10V-2Fe-3Al. Int. J. Hydrogen Energy 2015, 40, 16878-16891. [CrossRef]

32. Sun, Z.; Zhou, W.; Hou, H. Strengthening of Ti-6Al-4V alloys by thermohydrogen processing. Int. J. Hydrogen Energy 2009, 34, 1971-1976. [CrossRef]

33. Shen, C.C.; Perng, T.P. Pressure-composition isotherms and reversible hydrogen-induced phase transformations in Ti-6Al-4V. Acta Mater. 2007, 55, 1053-1058. [CrossRef]

34. Fang, T.Y.; Wang, W.H. Microstructural features on thermomechanical processing in a Ti-6Al-4V alloy. Mater. Chem. Phys. 1998, 56, 35-47. [CrossRef]

35. Sharma, B.; Vajpai, S.K.; Ameyama, K. Preparation of strong and ductile pure titanium via two-step rapid sintering of $\mathrm{TiH}_{2}$ powder. J. Alloys Compd. 2016, 683, 51-55. [CrossRef]

36. Murray, J.L. The Nb-Ti (Niobium-Titanium) system. Bull. Alloys Phase. Diagr. 1981, 2, 55-61. [CrossRef]

37. Suryanarayana, C. Mechanical alloying and milling. Prog. Mater. Sci. 2001, 46, 32-39. [CrossRef]

38. Pilarczyk, W.; Nowosielski, R.; Scymczak, M. The influence of initial powder properties on the mechanical alloying process and the final powders structure. J. Achiev. Mater. Manuf. Eng. 2011, 48, 169-176.

39. Benjamin, J.S.; Volin, T.E. The mechanism of mechanical alloying. Metall. Trans. 1974, 5, 1929-1934. [CrossRef]

40. Bair, J.; Zaeem, M.A.; Tonks, M. A review on hydride precipitation in zirconium alloys. J. Nucl. Mater. 2015, 466, 12-20. [CrossRef]

41. Celiz, Z.E.; Saumell, M.L.; Versaci, R.A.; Bozzano, P.B. Microstructural characterization of excel zirconium alloys. Procedia Mater. Sci. 2015, 8, 442-450. [CrossRef]

42. Luppo, M.I.; Politi, A.; Vigna, G. Hydrides in $\alpha$-Ti: Characterization and effect of applied external stresses. Acta Mater. 2005, 53, 4987-4996. [CrossRef]

43. Bhosle, V.; Baburaj, E.G.; Miranova, M.; Salama, K. Dehydrogenation of $\mathrm{TiH}_{2}$. Mater. Eng. A 2003, 356, 190-199. [CrossRef]

44. Senkov, O.N.; Chakoumakos, B.C.; Jonas, J.J.; Froes, F.H. Effect of temperature and hydrogen concentration on the lattice parameter of beta titanium. Mater. Res. Bull. 2001, 36, 1431-1440. [CrossRef]

45. Kim, H.Y.; Ikehara, Y.; Kim, J.I.; Hosoda, H.; Miyazaki, S. Martensitic transformation, shape memory effect and superplasticity of Ti-Nb binary alloys. Acta Mater. 2006, 54, 2419-2429. [CrossRef]

46. Chang, L.L.; Wang, Y.D.; Ren, Y. In-situ investigation of stress-induced martensitic transformation in Ti-Nb binary alloys with low Young's modulus. Mater. Sci. Eng. A 2016, 651, 442-448. [CrossRef]

47. Bonisch, M.; Calin, M.; Giebeler, L.; Helth, A.; Gebert, A.; Skrotzki, W.; Eckert, J. Composition-dependent magnitude of atomic shuffles in Ti-Nb martensites. J. Appl. Cryst. 2014, 47, 1374-1379. [CrossRef]

48. Morasch, K.R.; Bahr, D.F. The effects of hydrogen on deformation and cross slip in a BCC titanium Alloys. Scr. Mater. 2001, 45, 839-845. [CrossRef]

49. Dieter, G.E. Mechanical Metallurgy, 2nd ed.; McGraw-Hill Book Co.: New York, NY, USA, 1976; pp. $325-337$.

50. Alvarez, A.M.; Robertson, I.M.; Birnbaum, H.K. Hydrogen embrittlement of a metastable $\beta$-titanium alloy. Acta Mater. 2004, 52, 4161-4175. [CrossRef]

51. Hon, Y.H.; Wang, J.Y.; Pan, Y.N. Composition/Phase structure and properties of Titanium-Niobium alloys. Mater. Trans. 2003, 44, 2384-2390. [CrossRef] 
52. Zhao, D.; Chang, K.; Ebel, T.; Qian, M.; Willuneit, R.; Yan, M.; Pyczak, F. Microstructure and mechanical behavior of metal injection molded Ti-Nb binary alloys as biomedical material. J. Mech. Behav. Biomed. Mater. 2013, 28, 171-182. [CrossRef] [PubMed]

53. Kim, H.Y.; Satoru, H.; Kim, J.I.; Hosoda, H.; Miyazaki, S. Mechanical properites and shape memory behavior of Ti-Nb alloys. Mater. Trans. 2004, 45, 2443-2448. [CrossRef] 